\title{
Prevalence and antimicrobial susceptibility of non-typhoidal Salmonella (NTS) from salad vegetables at farms and retail markets in Terengganu, Malaysia
}

\author{
${ }^{1,2}$ Haslinda, W.H., ${ }^{1, *}$ Tang, J.Y.H., ${ }^{3}$ Tuan Zainazor, T.C., ${ }^{2}$ Mohd Khairi Hilman, A.L., \\ ${ }^{2}$ Wan Norezah, W.M., ${ }^{2}$ Irdawaty, T. and ${ }^{2}$ Noor Hafizatulakmal, H. \\ ${ }^{1}$ Faculty of Bioresources and Food Industry, Universiti Sultan Zainal Abidin, 22200 Besut, Terengganu, \\ Malaysia \\ ${ }^{2}$ Food Safety and Quality Laboratory, Terengganu State Health Department, Kg. Bukit Tunggal, 21200 \\ Kuala Nerus, Terengganu, Malaysia \\ ${ }^{3}$ Faculty of Fisheries and Food Science, Universiti Malaysia Terengganu, 21030 Kuala Nerus, Terengganu, \\ Malaysia
}

\section{Article history:}

Received: 5 July 2021

Received in revised form: 14 August 2021

Accepted: 27 September 2021

Available Online: 28

February 2022

\section{Keywords:}

Salad vegetables,

Non-typhoidal Salmonella,

Salmonella serovars,

Antimicrobial resistant.

DOI:

https://doi.org/10.26656/fr.2017.6(1).493

\begin{abstract}
In recent years, the consumption of vegetables has increased due to their health benefits. There are several foodborne outbreaks related to raw vegetable consumption and nontyphoidal Salmonella (NTS) is one of them. In connection with the worrying issue, this study was conducted to determine the occurrence of NTS from salad vegetables from farms, wet markets and supermarkets, and antimicrobial susceptibility profiling of NTS isolates. Samples were collected from farms $(n=270)$, wet markets $(n=216)$ and supermarkets $(\mathrm{n}=180)$ in Kuala Terengganu and Kuala Nerus, Terengganu. The samples were analysed according to International Standard protocol ISO 6579:2002(E) and serotyping was performed by Ipoh Public Health Laboratory, Perak. The isolated NTS from the samples were tested resistant against 20 antibiotics of clinical and agricultural importance. Out of 666 samples analyzed, $58(8.71 \%)$ samples were NTS positive. The prevalence of NTS in samples from farms, wet markets and supermarkets were found to be $2.96 \%(\mathrm{n}=8), 20.37 \%(\mathrm{n}=44)$ and $3.33 \%(\mathrm{n}=6)$, respectively. The serotyping analysis had identified 23 NTS serovars, the most predominant was Salmonella enterica serovar Weltevreden $(20.69 \%)$, followed by Salmonella enterica serovar Albany (10.34\%), Salmonella enterica serovar Hvittingfoss (8.62\%) and Salmonella enterica serovar Aberdeen (6.90\%). Among the isolates, 34.48\% (20/58) showed resistance toward at least one antibiotic tested with $95 \%$ of them were the isolates from wet markets. Resistances among isolates were observed in the highest rate for ampicillin (20.69\%), followed by tetracycline (18.97\%), doxycycline (17.24\%), trimethoprim-sulfamethoxazole (17.24\%) and chloramphenicol (15.52\%). Multidrug-resistant (MDR) characteristic was found in six serovars and S. enterica serovar Albany represents the highest prevalence of $83.33 \%$. One and two isolates were also found resistant toward ertapenem and colistin (last resort antibiotics), respectively. Based on the findings, salad vegetables can be considered as one of the important vehicles of MDR NTS to cause salmonellosis in humans. The wet market shows a significant risk of transmitting MDR NTS through vegetables. Thus, it is important to have proper handling to prevent cross-contamination of Salmonella in vegetables.
\end{abstract}

\section{Introduction}

The government of Malaysia through the Ministry of Agriculture and Food Industry has highlighted the importance of salad vegetables (locally known as ulam) consumption among Malaysian due to their nutritional value (Roshila-Murni, 2020) such as vitamins, minerals, dietary fibre and polyphenolic compounds (Sebastian et al., 2019). Salad vegetables such as ulam raja (cosmos), selom (water parsley), pegaga (pennywort), timun (cucumber), kacang botor (winged bean) and bayam brazil (sissoo spinach) are commonly available at retail markets all over the country. The recommended daily intake of vegetables for Malaysians is at least three servings which are equal to $240 \mathrm{~g}$ (Malaysian Dietary 
Guidelines, 2010).

Despite the health benefits, salad vegetables have also been associated with contamination of enteric pathogens such as Salmonella spp., Listeria monocytogenes, thermophilic Campylobater spp. and enterohaemorrhagic Escherichia coli (Khalid et al., 2015; Tang et al., 2016; Koukkidis and Freestone, 2018; Mohd Noor et al., 2020). Pathogens contaminate vegetables via direct or indirect contact with humans, livestock, wild animals, manure and irrigation water (Mir et al., 2018). Thus, the microbial safety of salad vegetables is of concern as these foods are consumed raw. Salad vegetables have been recognized as one of the most common sources of foodborne illness (Crowe et al., 2015). Several reports indicated that foodborne outbreaks associated with fresh vegetables were mostly caused by non-typhoidal Salmonella (NTS) (Yang et al., 2020). According to the European Food Safety Authority (EFSA), ready-to-eat leafy vegetables were ranked in the first place in terms of outbreak occurrence risk due to the presence of Salmonella (McLauchlin, 2014).

NTS is a major foodborne pathogen causing diarrhoeal illness (Chang et al., 2020). Each year, NTS causes approximately 93.8 million cases of acute gastroenteritis and 155,000 human deaths worldwide (Chang et al., 2020). Gastroenteritis caused by NTS is commonly mild, self-limiting and does not require treatment, however, antibiotic therapy is necessary for severe and invasive infections such as bacteremia, septic arthritis, and meningitis mostly in children and the immunocompromised (Chang et al., 2020; Yang et al., 2020).

During the last few years, the prevalence of antibiotic-resistant and multidrug-resistant (MDR) Salmonella isolated from fresh vegetables was increased in Malaysia (Abatcha et al., 2018; Thung et al., 2020) as well as in other countries worldwide (Abatcha et al., 2020; Yang et al., 2020). A review by Abatcha et al. (2020) involving reports from several countries found relatively high resistances among Salmonella from raw vegetables towards erythromycin $(82.3 \%)$, furazolidone $(62.9 \%)$, streptomycin $(49.6 \%)$, cefoperazone $(48.6 \%)$, kanamycin $(48.5 \%)$, cephalothin $(44.7 \%)$ and amoxicillin-clavulanic acid (37.8\%). Of particular concern is the probability of Salmonella strains to show resistance toward medically important classes of antibiotics such as extended-spectrum cephalosporins, fluoroquinolones, macrolides, aminoglycosides and penicillins which might compromise the treatment of complicated infections (Scott et al., 2019).

Therefore, this study was conducted to determine the prevalence of Salmonella in salad vegetables from farms and retail outlets in Terengganu, Malaysia and their antibiotic susceptibility patterns. The findings in this study were expected to describe the role of salad vegetables as a vehicle of Salmonella transmission with their MDR characteristic in the food chain.

\section{Materials and methods}

\subsection{Sample collection}

A total of 666 samples were collected from farms (270), wet markets (216) and supermarkets (180) of Kuala Terengganu and Kuala Nerus city in Terengganu, Malaysia during the period of January to December 2020. Five commercial farms located at Gong Badak $(5.36853,103.08281$; 5.36788,103.08352; $5.36785,103.08279 ; \quad 5.36697,103.08273)$ and Manir (5.30918,103.08382), four wet markets at Bukit Tunggal (5.33705,103.10704), Batu Enam (5.34656,103.09182), Manir (5.30945,103.08198), Chabang Tiga $(5.31743,103.12511)$ and four supermarkets in Kuala Terengganu $\quad(5.31115,103.13057 ; \quad 5.31057,103.12814)$ and Kuala Nerus (5.35539,103.09601; $5.35923,103.09881)$ were selected as sampling locations. Descriptions of the samples were summarized in Table 1. Sample of approximately $250 \mathrm{~g}$ was aseptically transferred into sterile bags ( $3 \mathrm{M}^{\mathrm{TM}}$ plain sample bag) and transported to the laboratory in an icebox to maintain a temperature of $1-4^{\circ} \mathrm{C}$.

\subsection{Salmonella isolation and identification}

Isolation of Salmonella from samples was carried out according to the International Standard protocol ISO 6579:2002(E) (ISO, 2002). For the first enrichment, $25 \mathrm{~g}$ of sample was weighed in a sterile stomacher bag and mixed thoroughly with $225 \mathrm{~g}$ of buffered peptone water (BPW) (Merck, 107228, Germany) prior to incubation at $37 \pm 1^{\circ} \mathrm{C}$ for $18 \pm 2 \mathrm{hr}$. Then, $0.1 \mathrm{~mL}$ and $1 \mathrm{~mL}$ of the preenriched cultures were incubated in $10 \mathrm{~mL}$ of RappaportVassiliadis medium with soy (RVS) (Oxoid, CM0669, UK) at $41.5 \pm 1{ }^{\circ} \mathrm{C}$ for $24 \pm 3 \mathrm{hrs}$ and $10 \mathrm{~mL}$ of MullerKauffmann Tetrathionate novobiocin (MKTTn) broth (Merck, 105878, Germany) at $37 \pm 1{ }^{\circ} \mathrm{C}$ for $24 \pm 3$ hrs, respectively. Cultures obtained were then inoculated on the surface of Xylose Lysine Deoxycholate (XLD) agar (Merck, 105287, Germany) and Bismuth Sulphite (BS) agar (Oxoid, CM0201, UK) prior to incubation at $37 \pm 1^{\circ}$ C for $24 \pm 2 \mathrm{hrs}$ and $48 \pm 2 \mathrm{hrs}$, respectively to obtain wellisolated colonies. Suspected colonies of Salmonella were subjected to biochemical (TSI, urea hydrolysis, lysine decarboxylation, $\beta$-galactosidase and indole reactions) and serological $(\mathrm{O}, \mathrm{H}$, and $\mathrm{Vi}$ antigens) tests for confirmation. Salmonella enterica subsp. enterica serovar Typhimurium ATCC 14028 and Citrobacter freundii ATCC 43864 were used as positive and negative 
Table 1. Descriptions of samples taken at farms, wet markets and supermarkets

\begin{tabular}{|c|c|c|c|c|c|}
\hline \multicolumn{3}{|c|}{ Type of sample } & \multicolumn{3}{|c|}{ No. of sample } \\
\hline Local name & Common name & Scientific name & Farms & Wet markets & Supermarkets \\
\hline Ulam raja & Cosmos & Cosmos caudatus & 27 & 36 & 36 \\
\hline Selom & Water parsley & Ooenanthe javanica & 36 & 36 & 27 \\
\hline Pegaga & Pennywort & Centella asiatica & 18 & 36 & 36 \\
\hline Timun & Cucumber & Cucumis sativus & 9 & 36 & 36 \\
\hline Kacang botor & Winged bean & Psophocarpus tetragonolobus & 9 & 36 & 36 \\
\hline Bayam brazil & Sissoo spinach & Alternanthera sissoo & 36 & 36 & 9 \\
\hline \multicolumn{3}{|c|}{ Irrigation water } & 45 & $-^{a}$ & - \\
\hline \multicolumn{3}{|c|}{ Soil } & 45 & - & - \\
\hline \multicolumn{3}{|c|}{ Manure } & 45 & - & - \\
\hline \multicolumn{3}{|c|}{ Total } & 270 & 216 & 180 \\
\hline
\end{tabular}

control, respectively. All the isolates were sent to the reference laboratory (Ipoh Public Health Laboratory) in Perak, Malaysia for serotyping.

\subsection{Antimicrobial susceptibility testing}

All Salmonella isolates were tested for their susceptibility against 20 antimicrobial agents (Oxoid, UK) viz. ampicillin (AMP, $10 \mu \mathrm{g}$ ), Amoxycillinclavulanic acid (AMC, $20 \mu \mathrm{g} / 10 \mu \mathrm{g}$ ), ampicillinsulbactam (SAM, 10 $\mu \mathrm{g} / 10 \mu \mathrm{g})$, piperacillin-tazobactam (TZP, $100 \mu \mathrm{g} / 10 \mu \mathrm{g}$ ), aztreonam (ATM, $30 \mu \mathrm{g}$ ), ertapenem (ETP, $10 \mu \mathrm{g})$, imipenem (IPM, $10 \mu \mathrm{g}$ ), meropenem (MEM, $10 \mu \mathrm{g})$, cefotaxime (CTX, 30 $\mu \mathrm{g}$ ), ceftazidime (CAZ, $30 \mu \mathrm{g}$ ), cefoperazone (CFP, $75 \mu \mathrm{g}$ ), cefepime (FEP, $30 \mu \mathrm{g}$ ), ceftriaxone (CRO, 30 $\mu \mathrm{g}$ ), tetracycline (TE, $30 \mu \mathrm{g}$ ), doxycycline (DO, $30 \mu \mathrm{g}$ ), minocycline $(\mathrm{MH}, \quad 30 \mu \mathrm{g})$, trimethoprimsulfamethoxazole (SXT, $1.25 \mu \mathrm{g} / 23.75 \mu \mathrm{g}$ ), azithromycin (AZM, $15 \mu \mathrm{g}$ ), chloramphenicol (C, $30 \mu \mathrm{g}$ ) and colistin (COL). The standard Kirby-Bauer disc diffusion method (Bauer et al., 1966) was used except for the colistin test. Standards and interpretive criteria described by the guidelines of the Clinical and Laboratory Standards Institute (CLSI, 2018) was referred for the interpretation of the disc diffusion method of testing with Escherichia coli ATCC 25922 as the reference strain. Susceptibility toward colistin was tested by the minimum inhibitory concentration (MIC) method using the Sensititre ${ }^{\circledR}$ FRCOL plates (TREK Diagnostic Systems, UK). The interpretation was done according to the breakpoint tables for interpretation of MICs and zone diameters version 9.0, recommended by the European Committee on Antimicrobial Susceptibility Testing (EUCAST, 2019). The MICs of colistin against E. coli ATCC 25922 and Pseudomonas aeruginosa ATCC27853 were determined as quality control. The multiple antibiotic resistance (MAR) index was determined according to the method stated by Krumperman (1983). MAR index $=a / b$ ( $a=$ number of antibiotics to which the particular isolate was resistant, $b=$ total number of antibiotics tested).

\section{Results}

All farms involved in this study were operated traditionally in a controlled environment with proper management. Their farming areas were well separated from other nearby activities with appropriate fencing. The farmers used treated animal waste manure for fertilization and untreated water for irrigation. Their preference for untreated water is due to cost-saving and non-chlorinated properties as the chlorine toxicity to plants is a concern for them. The overall characteristics of each farm were summarized in Table 2.

The isolation of Salmonella in this study was presented in Table 3. Overall, Salmonella was found in 8 (2.96\%), 44 (20.37\%) and 6 (3.33\%) samples collected from farms, wet markets and supermarkets, respectively. The wet market showed the highest incidence of Salmonella compared to the supermarket and farm, all varieties of salad vegetables from wet markets were contaminated at different percentages with the most contaminated were selom and pegaga (36.11\%). Among samples taken at the farm, Salmonella was mostly found in irrigation water (11.11\% of water samples tested). In soil samples, the percentage of Salmonella detection was $2.22 \%$. Interestingly, Salmonella was not found in all manure samples tested.

Table 2. Characteristics of each farm involved as sampling point

\begin{tabular}{cccccc}
\hline Characteristics & Farm I & Farm II & Farm III & Farm IV & Farm V \\
\hline Location & Flat land, village & Flat land, village & Flat land, village & Flat land, village & Flat land, village \\
Management & Traditional & Traditional & Traditional & Traditional & Traditional \\
Fertilizer & Treated manure & Treated manure & Treated manure & Treated manure & Treated manure \\
Irrigation source & Well water & Stream water & Well water & Well water & Well water \\
Fencing & Yes & Yes & Yes & Yes & Yes \\
\hline
\end{tabular}


Table 3. Contamination of Salmonella in samples from farms, wet markets and supermarkets

\begin{tabular}{|c|c|c|c|c|}
\hline Location & Sample & Sample size & Positive rate of Salmonella (\%) & Salmonella serovars (no. of strains) \\
\hline \multirow{10}{*}{ 蛋 } & Ulam raja & 27 & $2(7.41)$ & S. enterica ser. Augustenborg (2) \\
\hline & Selom & 36 & $0(0)$ & \multirow{9}{*}{$\begin{array}{c}\text { S. enterica ser. Weltevreden (3), Subsp. Iiib } \\
\text { Ser 47; C; Z35 (1), Subsp Ii } \\
\text { Ser47:enx,z15:1,6 (1) } \\
\text { S. enterica } \text { ser. Weltevreden (1) }\end{array}$} \\
\hline & Pegaga & 18 & $0(0)$ & \\
\hline & Timun & 9 & $0(0)$ & \\
\hline & Kacang botor & 9 & $0(0)$ & \\
\hline & Bayam brazil & 36 & $0(0)$ & \\
\hline & & & & \\
\hline & Irrigation water & 45 & $5(11.11)$ & \\
\hline & Soil & 45 & $1(2.22)$ & \\
\hline & Manure & 45 & $0(0)$ & \\
\hline & Total & 270 & $8(2.96)$ & \multirow{7}{*}{$\begin{array}{r}\text { S. enterica ser. Weltevreden (2), S. enterica } \\
\text { ser. Albany (3), S. enterica ser. Newport (1), } \\
\text { S. enterica ser. Hindmarsh (1) } \\
\text { S. enterica ser. Weltevreden (4), S. enterica } \\
\text { ser. Virginia (1), S. enterica ser. Aberdeen } \\
\text { (2), S. enterica ser. Bareilly (1), S. enterica } \\
\text { ser. Hvittingfoss (2), S. enterica ser. Virchow } \\
\text { (1), S. enterica ser. Saintpaul (1), S. enterica } \\
\text { ser. Kentucky (1) } \\
\text { S. enterica ser. Rubislaw (1), S. enterica ser. } \\
\text { Rissen (1), S. enterica ser. Newport (1), S. } \\
\text { enterica ser. Saintpaul (1), S. enterica ser. } \\
\text { Albany (2), S. enterica ser. Poona (3), S. en- } \\
\text { terica ser. Hvittingfoss (1), S. enterica ser. } \\
\text { Aberdeen (1), S. enterica ser. Corvallis (2) } \\
\text { S. enterica ser. Weltevreden (1), S. enterica } \\
\text { ser. Stanley (1) } \\
\text { S. enterica ser. Stanley (1), S. enterica ser. } \\
\text { Muenchen (1) } \\
\text { S. enterica ser. Weltevreden (1), S. enterica } \\
\text { ser. Hvittingfoss (1), S. enterica ser. Albany } \\
\text { (1), S. enterica ser. Corvallis (1), S. enterica } \\
\text { ser. Aberdeen (1), S. enterica ser. Agona (1), }\end{array}$} \\
\hline \multirow{6}{*}{ 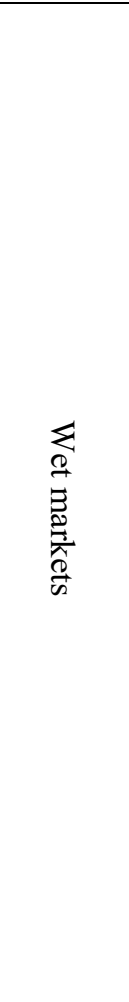 } & Ulam raja & 36 & $7(19.44)$ & \\
\hline & Selom & 36 & $13(36.11)$ & \\
\hline & Pegaga & 36 & $13(36.11)$ & \\
\hline & Timun & 36 & $2(5.56)$ & \\
\hline & Kacang botor & 36 & $2(5.56)$ & \\
\hline & Bayam brazil & 36 & $7(19.44)$ & \\
\hline & Total & 216 & $44(20.37)$ & \multirow{7}{*}{$\begin{array}{c}\text { S. enterica ser. Mountpleasant (1), S. enterica } \\
\text { ser. Braenderup (1), S. enterica ser. Lexing- } \\
\text { ton (1) } \\
\text { S. enterica ser. Lexington (1) } \\
\text { S. enterica ser. Hvittingfoss (1), S. enterica } \\
\text { ser. Rissen (1) }\end{array}$} \\
\hline \multirow{6}{*}{ 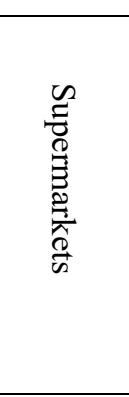 } & Ulam raja & 36 & $3(8.33)$ & \\
\hline & Selom & 27 & $1(3.70)$ & \\
\hline & Pegaga & 36 & $2(5.56)$ & \\
\hline & Timun & 36 & $0(0)$ & \\
\hline & Kacang botor & 36 & $0(0)$ & \\
\hline & Bayam brazil & 9 & $0(0)$ & \\
\hline & Total & 180 & $6(3.33)$ & \\
\hline & and total & 666 & $58(8.71)$ & \\
\hline
\end{tabular}

The distribution of Salmonella serovars isolated in this study was shown in Table 4. Of 58 isolates, 23 nontyphoidal Salmonella (NTS) serovars were identified, the most predominant serovar was $S$. enterica ser. Weltevreden $(20.69 \%)$, followed by $S$. enterica ser. Albany (10.34\%), S. enterica ser. Hvittingfoss (8.62\%) and $S$. enterica ser. Aberdeen (6.90\%).

Tables 5 and 6 show the antimicrobial susceptibility profiles and MAR index of the NTS isolates against 20 antibiotics. Among all, 20 (34.48\%) isolates showed resistance toward at least one antibiotic tested with 19 $(95 \%)$ and one $(5 \%)$ of them were the isolates from wet markets and supermarkets, respectively. All isolates from farms were susceptible to all antibiotics tested. The highest rate of resistance was observed for ampicillin $(20.69 \%)$, followed by tetracycline (18.97\%), doxycycline (17.24\%), trimethoprim-sulfamethoxazole (17.24\%) and chloramphenicol (15.52\%). Intermediate resistance was also detected for the antibiotics including 


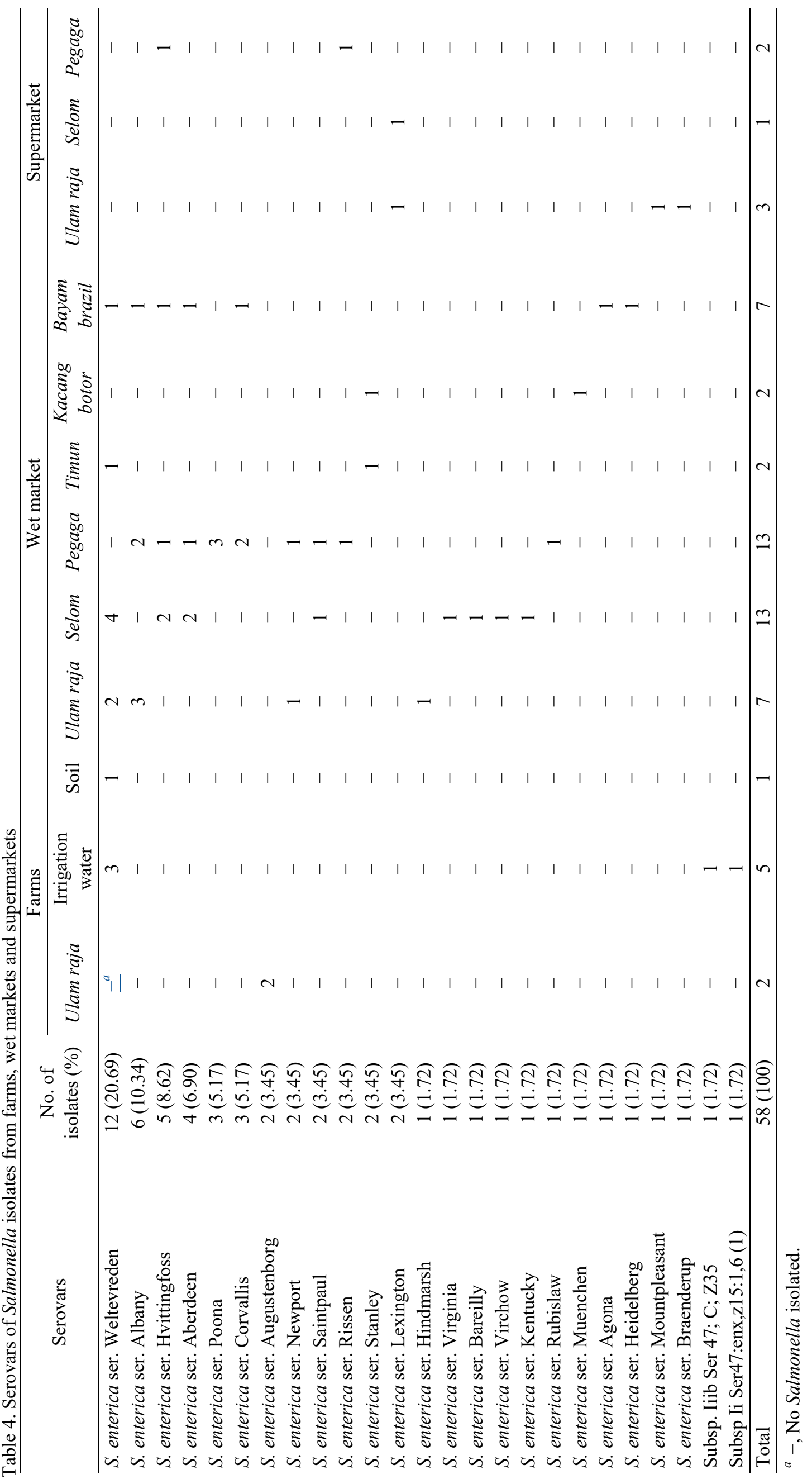


Table 5. Antibiotic resistance profiles and MAR index of Salmonella serovars from different sources

\begin{tabular}{|c|c|c|c|}
\hline Isolate code ${ }^{a}$ & Salmonella serovars & Resistance profile $^{b}$ & MAR index \\
\hline FUR1 & S. enterica ser. Augustenborg & $-c$ & $\mathrm{NA}^{d}$ \\
\hline FUR2 & S. enterica ser. Augustenborg & - & NA \\
\hline FIW1 & S. enterica ser. Weltevreden & - & NA \\
\hline FIW2 & S. enterica ser. Weltevreden & - & NA \\
\hline FIW3 & S. enterica ser. Weltevreden & - & NA \\
\hline FIW4 & Subsp. Iiib Ser 47; C; Z35 & - & NA \\
\hline FIW5 & Subsp Ii Ser47:enx,z15:1,6 & - & NA \\
\hline FSO1 & S. enterica ser. Weltevreden & - & NA \\
\hline WUR1 & S. enterica ser. Weltevreden & DO-AZM-COL & 0.15 \\
\hline WUR2 & S. enterica ser. Weltevreden & - & NA \\
\hline WUR3 & S. enterica ser. Albany & AMP-SAM-CFP-TE-SXT-C & 0.30 \\
\hline WUR4 & S. enterica ser. Albany & AMP-SXT-C & 0.15 \\
\hline WUR5 & S. enterica ser. Albany & AMP-SXT-C & 0.15 \\
\hline WUR6 & S. enterica ser. Newport & - & NA \\
\hline WUR7 & S. enterica ser. Hindmarsh & AMP-TE-DO-MH-C & 0.25 \\
\hline WSE1 & S. enterica ser. Weltevreden & ATM-AZM & NA \\
\hline WSE2 & S. enterica ser. Weltevreden & AMC-FEP & NA \\
\hline WSE3 & S. enterica ser. Weltevreden & AMP-AZM & NA \\
\hline WSE4 & S. enterica ser. Weltevreden & - & NA \\
\hline WSE5 & S. enterica ser. Virginia & TE-DO-MH & NA \\
\hline WSE6 & S. enterica ser. Aberdeen & - & NA \\
\hline WSE7 & S. enterica ser. Aberdeen & - & NA \\
\hline WSE8 & S. enterica ser. Bareilly & - & NA \\
\hline WSE9 & S. enterica ser. Hvittingfoss & - & NA \\
\hline WSE10 & S. enterica ser. Hvittingfoss & - & NA \\
\hline WSE11 & S. enterica ser. Virchow & - & NA \\
\hline WSE12 & S. enterica ser. Saintpaul & - & NA \\
\hline WSE13 & S. enterica ser. Kentucky & - & NA \\
\hline WP1 & S. enterica ser. Rubislaw & - & NA \\
\hline WP2 & S. enterica ser. Rissen & AMP-ATM-CTX-CAZ-CFP-FEP-CRO-TE-DO-SXT-C & 0.55 \\
\hline WP3 & S. enterica ser. Newport & - & NA \\
\hline WP4 & S. enterica ser. Saintpaul & - & NA \\
\hline WP5 & S. enterica ser. Albany & AMP- SXT-C & 0.15 \\
\hline WP6 & S. enterica ser. Albany & AMP-AMC-SAM- ATM-ETP-CFP- CRO-TE-SXT-C & 0.50 \\
\hline WP7 & S. enterica ser. Poona & - & NA \\
\hline WP8 & S. enterica ser. Poona & - & NA \\
\hline WP9 & S. enterica ser. Poona & - & NA \\
\hline WP10 & S. enterica ser. Hvittingfoss & AMP-CTX-TE-DO-MH-SXT-AZM-C-COL & 0.45 \\
\hline WP11 & S. enterica ser. Aberdeen & - & NA \\
\hline WP12 & S. enterica ser. Corvallis & TE-DO-MH & NA \\
\hline WP13 & S. enterica ser. Corvallis & - & NA \\
\hline WT1 & S. enterica ser. Weltevreden & AZM & NA \\
\hline WT2 & S. enterica ser. Stanley & - & NA \\
\hline WKB1 & S. enterica ser. Stanley & - & NA \\
\hline WKB2 & S. enterica ser. Muenchen & - & NA \\
\hline WBB1 & S. enterica ser. Weltevreden & - & NA \\
\hline WBB2 & S. enterica ser. Hvittingfoss & - & NA \\
\hline WBB3 & S. enterica ser. Albany & TE-DO-MH-SXT & NA \\
\hline WBB4 & S. enterica ser. Corvallis & AMP-SAM-TE-DO-SXT & 0.25 \\
\hline WBB5 & S. enterica ser. Aberdeen & - & NA \\
\hline WBB6 & S. enterica ser. Agona & TE-DO & NA \\
\hline WBB7 & S. enterica ser. Heidelberg & AMP-AMC & NA \\
\hline SUR1 & S. enterica ser. Mountpleasant & - & NA \\
\hline SUR2 & S. enterica ser. Braenderup & - & NA \\
\hline SUR3 & S. enterica ser. Lexington & - & NA \\
\hline SSE1 & S. enterica ser. Lexington & - & NA \\
\hline SP1 & S. enterica ser. Hvittingfoss & - & NA \\
\hline SP2 & S. enterica ser. Rissen & AMP-AMC-TE-DO-MH-SXT-C & 0.35 \\
\hline
\end{tabular}

${ }^{a}$ Isolate code: F (farm), W (wet market), S (supermarket), UR (ulam raja), IW (irrigation water), SO (soil), SE (selom), $\mathrm{P}$ (pegaga), T (timun), KB (kacang botor), BB (bayam brazil).

${ }^{b}$ Antimicrobial abbreviations: ampicillin (AMP), amoxycillin-clavulanic acid (AMC), ampicillin-sulbactam (SAM), piperacillin -tazobactam (TZP), aztreonam (ATM), ertapenem (ETP), imipenem (IPM), meropenem (MEM), cefotaxime (CTX), ceftazidime (CAZ), cefoperazone (CFP), cefepime (FEP), ceftriaxone (CRO), tetracycline (TE), doxycycline (DO), minocycline (MH), trimethoprim-sulfamethoxazole (SXT), azithromycin (AZM), chloramphenicol (C) and colistin (COL).

${ }^{c}-$, not resistant to any antimicrobial agents tested.

${ }^{d}$ NA: not available 
Table 6. Antimicrobial profiles of Salmonella toward different classes of antibiotic

\begin{tabular}{cllccc}
\hline No & \multicolumn{1}{c}{ Antibiotic class } & \multicolumn{1}{c}{ Antibiotics } & \multicolumn{3}{c}{ Antimicrobial profiles } \\
\cline { 3 - 5 }$\cdot$ & & & Susceptible (\%) & Intermediate (\%) & Resistant (\%) \\
\hline 1 & Penicillins & Ampicillin & $46(79.31)$ & - & $12(20.69)$ \\
2 & $\beta$-lactam/ & Amoxycillin-Clavulanic acid & $51(87.53)$ & $3(5.17)$ & $4(6.90)$ \\
& $\beta$-lactamase combination & Ampicillin-sulbactam & $50(86.21)$ & $5(8.62)$ & $3(5.17)$ \\
& & Piperacillin-tazobactam & $58(100)$ & - & - \\
3 & Monobactams & Aztreonam & $54(93.10)$ & $1(1.72)$ & $3(5.17)$ \\
4 & Carbapenems & Ertapenem & $57(98.28)$ & - & $1(1.72)$ \\
& & Imipenem & $58(100)$ & - & - \\
& & Meropenem & $56(96.55)$ & $2(3.45)$ & - \\
5 & Cephalosporins & Cefotaxime & $56(96.55)$ & - & $2(3.45)$ \\
& \multirow{2}{*}{$3^{\text {rd }}$ and 4 ${ }^{\text {th }}$ generation) $)$} & Ceftazidime & $57(98.28)$ & - & $1(1.72)$ \\
& & Cefoperazone & $49(84.48)$ & $6(10.34)$ & $3(5.17)$ \\
& & Cefepime & $55(94.83)$ & $3(5.17)$ & $3(5.17)$ \\
& & Ceftriaxone & $56(96.55)$ & - & $2(3.45)$ \\
6 & Tetracyclines & Tetracycline & $44(75.86)$ & $3(5.17)$ & $11(18.97)$ \\
& & Doxycycline & $47(81.03)$ & $1(1.72)$ & $10(17.24)$ \\
& & Minocycline & $50(86.21)$ & $3(5.17)$ & $5(8.62)$ \\
7 & Folate pathway antagonists & Trimethoprim-sulfamethoxazole & $48(82.76)$ & - & $10(17.24)$ \\
8 & Macrolides & Azithromycin & $53(91.38)$ & - & $5(8.62)$ \\
9 & Phenicols & Chloramphenicol & $49(84.48)$ & - & $9(15.52)$ \\
10 & Colistin & Colistin & $56(96.55)$ & - & $2(3.45)$ \\
\hline
\end{tabular}

${ }^{a}-$, None of the isolates showed related profile.

cefoperazone (10.34\%), ampicillin-sulbactam (8.62\%), amoxycillin-clavulanic acid, cefepime, tetracycline and minocycline $(5.17 \%$ each). Piperacillin-tazobactam and imipenem were effective in preventing the growth of NTS in this study with $100 \%$ susceptibility. An isolate of $S$. enterica ser. Albany from pegaga in the wet market was found resistant toward ertapenem. Colistin resistance was also demonstrated by one $S$. enterica ser. Weltevreden and $S$. enterica ser. Hvittingfoss from wet markets, isolated from ulam raja and pegaga, respectively. As shown in Table 5, 11 isolates (18.97\%) were MDR and $S$. enterica ser. Rissen was detected with the highest MAR index value of 0.55 . Both $S$. enterica ser. Rissen isolated in this study were MDR which exhibit resistance to at least five different classes of antibiotic. Among all different NTS serovars, six serovars showed MDR characteristics and S. enterica ser. Albany represent the highest prevalence with 5 $(83.33 \%)$ isolates exhibit MDR (Table 5).

\section{Discussion}

Finding on the prevalence of Salmonella in this study was in line with the previous study which reported a relatively high incidence of Salmonella in salad vegetables from the wet market including $21.5 \%$ in the northern and middle region of Malaysia (Abatcha et al., 2018), $12.9 \%$ in Mekong Delta, Vietnam (Nguyen et al., 2021 ) and $17.59 \%$ in Hue City, Vietnam (Chau et al., 2014). Cross-contamination through improper handling and poor hygienic practices might play a significant role as a source of Salmonella contamination to salad vegetables in the wet market, in addition, with the open display under ambient temperature, growth and multiplication of pathogenic bacteria including Salmonella will be promoted. In Malaysia, Nidaullah et al. (2017) reported consistent contamination of Salmonella (86.18\% detection) in the environmental samples collected along the wet market chicken processing line, suggesting that poultry from the wet market can be an important vehicle for the transmission of Salmonella. Since selling locations for poultry and vegetables are adjacent in the wet market, Salmonella might be transferred to the salad vegetables through unhygienic and poor sanitation practices among retailers and consumers. Rodents that inhabit the wet markets could also be considered as the reservoirs and transmitters of Salmonella to salad vegetables. A study by Ribas et al. (2016) reported $49.10 \%$ prevalence of Salmonella in rats from wet markets in Thailand, they have belonged to three serovars: $S$. enterica ser. Typhimurium (30\%), S. enterica ser. Weltevreden (12.7\%) and $S$. enterica ser. 4,[5],12:i:- (6.4\%). This finding indicates that rodents could act as a potential transmitter of Salmonella due to the contact they have with food products stored and sold in wet markets.

Overall occurrence of Salmonella in salad vegetables from a supermarket in this study was low, comparable to other studies in Malaysia (3.0\%) and Turkey (3.38\%) (Buyukunal et al., 2015; Saw et al., 2020). A supermarket is an organized grocery store selling a variety of goods. The goods were systematically arranged in different zones under specific conditions 
depending on the type of goods to avoid crosscontamination. The environment in a supermarket is commonly clean, tidy and cool with proper maintenance, these conditions are required to maintain the quality of goods, especially food items (Saw et al., 2020). All these circumstances might contribute to the low incidence of Salmonella in salad vegetables sold in a supermarket.

In this study, only two (1.48\%) Salmonella were detected from vegetable samples collected from the farm, this finding could be explained by the probability of low survivability of Salmonella on the vegetables during cultivation due to direct exposure to sunlight. According to Strawn, Gröhn, Warchocki et al. (2013), pathogens that present in soil are likely to contaminate vegetables, however, the presence of pathogens will decrease over time after cultivation, due to environmental conditions exposure such as ultraviolet light that reduces pathogen loads. Furthermore, the use of pesticides might be one of the causes of the low detection of Salmonella in farm vegetables, the pesticides have been shown to inhibit growth and kill soil microorganisms (Filimon et al., 2015). This finding was further evidenced by a study by Ottesen et al. (2015) which observed lower counts of Salmonella on tomato fruits and leaves that were regularly sprayed with pesticides as compared to controls that were not exposed to pesticides.

The prevalence of Salmonella from irrigation water in vegetable farms was also demonstrated by several other studies such as $12.5 \%$ in New York, USA, (Strawn, Gröhn, Warchocki et al., 2013), 7.7\% in California, USA (Benjamin et al., 2013) and 3.4\% in Kano, Nigeria (Abakpa et al., 2015). Through observation during the sampling process, all vegetable farmers involved in this study were found using irrigation pumps to water their crops from wells and streams (Table 3), sprinkler irrigation is the most common form of irrigation practised in the farms. Due to the usage of untreated water which is found to have Salmonella, vegetables might be contaminated through irrigation. Adetunde et al. (2015) revealed a strong positive correlation between the microbial counts on vegetables and in irrigation water, which makes it one of the main sources of vegetable contamination. Furthermore, the sprinkler method of irrigation used also contributed to the higher transfer and retention of bacteria on the edible portion of vegetables (Gupta and Madramootoo, 2017). Contamination of pathogens into streams and wells is commonly attributable to household or small industries wastewater (Keraita et al., 2014) and wild or domestic animals (Adetunde et al., 2015).

The detection of Salmonella in soil samples collected from farms was in agreement with other studies in Kano,
Nigeria (2.5\%) and New York, USA (2.0\%) (Strawn, Fortes, Bihn et al., 2013; Abakpa et al., 2015). Salmonella may enter the soil environment from various sources such as through contaminated water, manure, livestock and wildlife (Alegbeleye et al., 2018), their survivability in the soil is influenced by various factors such as temperature, moisture, soil type, presence of plants, $\mathrm{pH}$, nutrient availability, exposure to sun (ultraviolet) light and protozoan predation (Jacobsen and Bech, 2012). With regard to this study, the most probable source of Salmonella contamination into the soil is from untreated water used for irrigation, based on the prevalence of Salmonella in water samples analyzed. This finding could be related to a study by Leifert et al. (2008) which demonstrated the exposure of water through precipitation and irrigation as one of the most critical factors influencing microbial transport and survival in soil.

Our results suggest that the application of treated manure to fields can significantly decrease the risk of Salmonella contamination as none of the manure samples tested in this study were contaminated with Salmonella. All manure samples taken for this study were in the form of processed pellets of chicken faeces. The manure management practices, with regards to the collection, transport, handling, treatment, disposal and utilization might affect the survival of foodborne pathogens. Treatment methods for manure such as thermal, chemical, biological and physical are commonly used, all these types of treatment may reduce pathogen loads in manure before releasing into the environment (Alegbeleye and Sant'Ana, 2020). Different farms handle manure using various types of systems and their combinations, each treatment is capable of reducing pathogen loads in manure, even though the efficiency of different methods may vary (Millner, 2014).

S. enterica ser. Weltevreden was also reported as the most found serovar in salad vegetables from other studies in Vietnam (Nguyen et al., 2021), Malaysia (Abatcha et al., 2018) and Indonesia (Kusumaningrum et al., 2012). This serovar has been identified as the common pathogen associated with human salmonellosis in the South and South-East Asian regions (Gunasena and De Silva, 2021). S. enterica ser. Weltevreden was recognized for the first time to cause a salmonellosis outbreak related to plant products in Scandinavia (Norway, Denmark and Finland), this outbreak occurred in 2007 involving 45 cases resulting from consumption of contaminated alfalfa sprouts (Gunasena and De Silva, 2021). The capability of $S$. Weltevreden to grow and survive in a plant is possibly due to the presence of additional carbohydrate metabolism clusters in their genomes as compared to other serovars, which enable 
this serovar to metabolize carbohydrates better in plant tissue (Brankatschk et al., 2012). Brankatschk et al. (2012) also demonstrated the presence of genes for myoinositol utilization in $S$. enterica ser. Weltevreden isolates tested, the capability of this serovar to grow on stereoisomers of myo-inositol might also contribute to their survival on plants as this carbohydrate is commonly present in soil and the phosphorylated form of myoinositol is stored in plant tissue. The presence of these types of genes in $S$. enterica ser. Weltevreden might be considered as the reason for their capability to become prevalent in salad vegetable samples involved in this study.

A study on the prevalence of Salmonella in salad vegetables from Peninsular Malaysia by Abatcha et al. (2018) found a relatively comparable percentage of $S$. enterica ser. Albany (4.60\%), $S$. enterica ser. Hvittingfoss (5.75\%) and S. enterica ser. Aberdeen $(4.60 \%)$ with this present study. These serovars are rarely associated with salmonellosis outbreaks, however, in 2016, S. enterica ser. Hvittingfoss has been reported to cause outbreaks associated with fresh produce (cantaloupes) in Australia (Flynn, 2016).

On the other hand, S. enterica ser. Newport is one of the most important NTS serovars that has been associated with several major outbreaks due to consumption of raw vegetables such as alfalfa sprouts, tomatoes, lettuce and cucumber (El-Dougdoug et al., 2019; Yang et al., 2020). Latest in 2020, a multistate outbreak of $S$. enterica ser. Newport infections linked to onions affecting 1127 people from 48 states in the USA has been reported (CDC, 2020). This serovar has previously been listed among the three highest ranks of Salmonella serovars associated with foodborne outbreaks in the USA since 1970 (CDC, 2013). Furthermore, the Public Health Agency of Canada has listed S. enterica ser. Newport in the ten most commonly reported Salmonella serotypes in Canada accounting for human illness in 2018 (Government of Canada, 2020). In Malaysia, there is no published report of a foodborne outbreak associated with $S$. enterica ser. Newport so far. However, S. enterica ser. Newport was present in salad vegetables tested in this study and also in a study by Abatcha et al. (2018) with $3.45 \%$ and $2.30 \%$ detection, respectively. This indicates the probability for the occurrence of salmonellosis associated with salad vegetables contaminated with $S$. Newport in Malaysia.

Multiple types of other serovars were also found among samples tested (Table 4), the diversity of these serovars might have been influenced by the different sampling locations that were exposed to different sources of contamination (different farms, transports, retail outlets or retailers).

A few reports were published concerning the antibiotic-resistant Salmonella associated with vegetables in Malaysia and other Southeast Asian countries (Abatcha et al., 2018; Nguyen et al., 2021). Among the isolates recovered in this study, resistance to ampicillin, tetracycline and trimethoprimsulfamethoxazole occurred most frequently, these results are consistent with the report from a study of resistance among Salmonella isolates from raw vegetables in China (Yang et al., 2020). It is noteworthy that the highest resistance is toward ampicillin as this antibiotic is categorized as the critically important antibiotic with high priority in treating serious bacterial infections in people (Scott et al., 2019; WHO, 2019). Resistance toward tetracycline, doxycycline, trimethoprimsulfamethoxazole and chloramphenicol could also be of concern since these antibiotics are categorized as highly important for human medicine by the WHO (2019). All the resistant NTS found in this study were isolated from wet markets and supermarkets, thus, the most probable source of antibiotic resistance is from direct contamination of resistant isolates from humans during harvesting and handling of salad vegetables due to insufficient hygiene measures. Similarly, Mesbah Zekar et al. (2017) demonstrated that raw eaten vegetables at the market constitute a reservoir of resistant and MDR bacteria that might be reflected from improper hygiene practices during handling.

Attention should be given to the presence of ertapenem resistant $S$. enterica ser. Albany since carbapenems are the last line of antibiotics used to treat human infections caused by MDR bacteria (Monte et al., 2019). However, this finding is relatively low as compared to the finding by Igbinosa et al. (2017), who reported the presence of $16(22.22 \%)$ imipenem (carbapenem class of antibiotic) resistant Salmonella isolated from fresh vegetables. According to WHO (2019), there is still limited transmission of carbapenemresistant Salmonella from non-human sources, however, based on reports from several countries, the spread in the food chain is increasing. Carbapenem-resistant bacteria have caused severe outbreaks, the infections are difficult to treat and associated with high costs and mortality (Malchione et al., 2019). The increasing trend of carbapenem-resistance in bacteria necessitates a move to the usage of colistin as the last-resort antibiotic where this antibiotic is active against carbapenem-resistant bacteria (Malchione et al., 2019; Wakabayashi et al., 2020). The finding of colistin-resistant NTS in this study is comparable to a report by Verma et al. (2018) which found two $(7.7 \%)$ isolates of colistin-resistant Salmonella from vegetable samples examined. The 
emergence of colistin-resistant bacteria is a worldwide concern as this antibiotic is recognized as the last choice of antibiotic for the treatment of infections in hospitalized patients caused by carbapenem-resistant Gram-negative bacteria (Elbediwi et al., 2019). The presence of carbapenem and colistin-resistant NTS isolated from salad vegetables in this study, even in low percentage, indicate the emerging spread of resistance toward these last-resort antibiotics in the food chain.

The level of MDR NTS (18.97\%) in this study was lower than that previously reported by Abatcha et al. (2018) in Malaysia (55.1\%). Abatcha et al. (2018) also reported the presence of two $(50 \%)$ MDR isolates of $S$. Albany from vegetables with high MAR index of 0.66. Several other studies also reported the high prevalence of MDR among $S$. enterica ser. Albany such as in the chicken food chain in Cambodia (96.1\%), poultry processing plant and retail markets in South Korea (93.2\%) and chicken meat in Korea (80\%) (Shang et al., 2019; Vuthy et al., 2017; Sin et al., 2020). The MDR characteristics among most of $S$. enterica ser. Albany isolated in this study and also from others might indicate the specific $S$. enterica ser. Albany in the food chains have acquired resistance to various types of antimicrobial agents including the medically important antibiotics.

\section{Conclusion}

Findings in this study reveal the relatively high occurrence of NTS contamination of salad vegetables from wet markets in Terengganu, Malaysia, suggesting that salad vegetables could represent a potential source of salmonellosis. Furthermore, the resistance toward medically important antibiotics among NTS in this study highlight the potential risk to public health. More attention should be given to the presence of carbapenem and colistin-resistant isolates as these antibiotics are categorized as last-resort antibiotics in the treatment of severe foodborne illness cases. These data may contribute to providing useful information for the development of effective strategies to ensure the safety of salad vegetables sold at retail outlets in Malaysia.

\section{Conflict of interest}

The authors declare no conflict of interest.

\section{Acknowledgements}

The authors would like to thank the Director General of Health Malaysia for his permission to publish this article. This research was financially supported by the Food Safety and Quality Program, Ministry of Health Malaysia with approval reference no. KKM.600-19/7/5
Jld. 4(4). We also sincerely appreciate the technical support provided by the Food Safety and Quality Division, Terengganu State Health Department.

\section{References}

Abakpa, G.O., Umoh, V.J., Ameh, J.B., Yakubu, S.E., Kwaga, J.K.P. and Kamaruzaman, S. (2015). Diversity and antimicrobial resistance of Salmonella enterica isolated from fresh produce and environmental samples. Environmental Nanotechnology, Monitoring and Management, 3, 38 -46. https://doi.org/10.1016/j.enmm.2014.11.004

Abatcha, M.G., Goni, M.D., Abbas, M.A., Jalo, I.M. and Mohammed, G. (2020). A review of Listeria and Salmonella: an update on description, characteristics, incidence, and antibiotic susceptibility. Advances in Animal and Veterinary Sciences, 8(11), 1232-1249. https://doi.org/10.17582/ journal.aavs/2020/8.11.1232.1249

Abatcha, M.G., Effarizah., M.E. and Rusul, G. (2018). Prevalence, antimicrobial resistance, resistance genes and class 1 integrons of Salmonella serovars in leafy vegetables, chicken carcasses and related processing environments in Malaysian fresh food markets. Food Control, 91, 170-180. https:// doi.org/10.1016/j.foodcont.2018.02.039

Adetunde, L., Sackey, I., Dombirl, D. and Mariama, Z. (2015). Potential links between irrigation water microbiological quality and fresh vegetables quality in Upper East region of Ghana subsistence farming. Annual Research and Review in Biology, 6(6), 347354. https://doi.org/10.9734/ARRB/2015/8273

Alegbeleye, O.O., Singleton, I. and Sant'Ana, A.S. (2018). Sources and contamination routes of microbial pathogens to fresh produce during field cultivation: A review. Food Microbiology, 73, 177208. https://doi.org/10.1016/j.fm.2018.01.003

Alegbeleye, O.O. and Sant'Ana, A.S. (2020). Manureborne pathogens as an important source of water contamination: An update on the dynamics of pathogen survival/transport as well as practical risk mitigation strategies. International Journal of Hygiene and Environmental Health, 227, 13524. https://doi.org/10.1016/j.ijheh.2020.113524

Benjamin, L., Atwill, E.R., Jay-Russell, M., Cooley, M., Carychao, D., Lisa Gorski, L. and Mandrell, R.E. (2013). Occurrence of generic Escherichia coli, Escherichia coli $\mathrm{O} 157$ and Salmonella spp. in water and sediment from leafy green produce farms and streams on the Central California coast. International Journal of Food Microbiology, 165(1), 65-76. https://doi.org/10.1016/j.ijfoodmicro.2013.04.003 
Bauer, A.W., Kirby, W.M.M., Sherris, J.G. and Turk, A. (1966). Antimicrobial susceptibility testing by standardized single disc method. American Journal of Clinical Pathology, 45(4), 493-496. https:// doi.org/10.1093/ajcp/45.4_ts.493

Brankatschk, K., Blom, J., Goesmann, A., Smits, T.H.M. and Duffy, B. (2012). Comparative genomic analysis of Salmonella enterica subsp. enterica serovar Weltevreden foodborne strains with other serovars. International Journal of Food Microbiology, 155(3), 247-256. https://doi.org/10.1016/ j.ijfoodmicro.2012.01.024

Buyukunal, S.K., Issa, G., Aksu, F. and Vural, A. (2015). Microbiological quality of fresh vegetables and fruits collected from supermarkets in Istanbul, Turkey. Journal of Food and Nutrition Sciences, 3(4), 152159. https://doi.org/10.11648/j.jfns.20150304.13

CDC (Centers for Disease Control and Prevention) (2013). National Enteric Disease Surveillance: Salmonella Annual Report, 2011. Atlanta, USA: CDC.

CDC (Centers for Disease Control and Prevention) (2020). Outbreak of Salmonella Newport Infections Linked to Onions. Retrieved from CDC website: https://www.cdc.gov/salmonella/newport-07-20/ index.htmL.

Chang, Y.-J., Chen, M.-C., Feng, Y., Su, L.-H., Li, H.C., Yang, H.-P., Yu, M.-J., Chen, C.-L. and Chiu, C. -H. (2020). Highly antimicrobial-resistant Nontyphoidal Salmonella from retail meats and clinical impact in children, Taiwan. Pediatrics and Neonatology, 61(4), 432-438. https:// doi.org/10.1016/j.pedneo.2020.03.017

Chau, H.L.Q., Thong, H.T., Chao, N.V., Hung, P.H.S., Hai, V.V., An, L.V., Fujieda, A., Ueru, T. and Akamatsu, M. (2014). Microbial and parasitic contamination on fresh vegetables sold in traditional markets in Hue City, Vietnam. Journal of Food and Nutrition Research, 2(12), 959-964. https:// doi.org/10.12691/jfnr-2-12-16

CLSI (Clinical and Laboratory Standards Institute). (2018). Performance Standards for Antimicrobial Susceptibility Tesing, Twenty Second Informational Supplement. CLSI document M100-S22. Wayne, USA: CLSI.

Crowe, S.J., Mahon, B.E., Vieira, A.R. and Gould, L.H. (2015). Vital Signs: Multistate Foodborne Outbreaks - United States, 2010-2014. Morbidity Mortality Weekly Report, 64(45), 1221-1225. https:// doi.org/10.15585/mmwr.mm6443a4

Elbediwi, M., Li, Y., Paudyal, N., Pan, H., Li, X., Xie, S., Rajkovic, A., Feng, Y., Fang, W., Rankin, S.C. and Yue, M. (2019). Global Burden of ColistinResistant Bacteria: Mobilized Colistin Resistance Genes Study (1980-2018). Microorganisms, 7(10), 461.

microorganisms 7100461

El-Dougdoug, N.K., Cucic, S., Abdelhamid, A.G., Brovko, L., Kropinski, A.M., Griffiths, M.W. and Anany, H. (2019). Control of Salmonella Newport on cherry tomato using a cocktail of lytic bacteriophages. International Journal of Food Microbiology, 293, 60-71. https://doi.org/10.1016/ j.ijfoodmicro.2019.01.003

EUCAST (European Committee on Antimicrobial Susceptibility Testing). (2019). EUCAST Breakpoint tables for interpretation of MICs and zone diameters. Version 9.0, 2019. Retrieved from http:// www.eucast.org.

Filimon, M.N., Voia, S.O., Popescu, R., Dumitrescu, G., Ciochina, L.P., Mituletu, M. and Vlad, D.C. (2015). The effect of some insecticides on soil microorganisms based on enzymatic and bacteriological analyses. Romanian Biotechnological Letters, 20(3), 10439-10447.

Flynn, D. (2016). How did Salmonella Hvittingfoss get on Aussie rockmelons? Retrieved from Food Safety News website: https:// www.foodsafetynews.com/2016/08/130219/

Government of Canada. (2020). National Enteric Surveillance Program Annual Summary 2018. Guelph, Canada: Public Health Agency of Canada.

Gunasena, J.B. and De Silva, S.T. (2021). An unusual case of sepsis due to Salmonella enterica serovar Weltevreden, an emerging pathogen of nontyphoidal salmonellosis. Tropical Doctor, 51(4), 634 -637. https://doi.org/10.1177/0049475520979302

Gupta, D. and Madramootoo, C.A. (2017). Escherichia coli contamination on ready-to-eat (RTE), Lettuce. Expo Health, 9(4), 1-11. https://doi.org/10.1007/ s12403-016-0236-4

Igbinosa, E.O., Beshiru, A., Isichei-Ukah, B.O., Oghoye P. and Oyedoh, O.P. (2017). Isolation and characterization of multiple antibiotic-resistant Salmonella strains from fresh vegetable samples. Nigerian Journal of Microbiology, 31(2), 40994106.

ISO (International Organization for Standardization). (2002). ISO 6579:2002, Microbiology of food and animal feeding stuffs - Horizontal method for the detection of Salmonella spp., Geneva, Switzerland.

Jacobsen, C.S. and Bech, T.B. (2012). Soil survival of Salmonella and transfer to freshwater and fresh produce. Food Research International, 45(2), 557- 
566. https://doi.org/10.1016/j.foodres.2011.07.026

Keraita, B., Silverman, A., Amoah, P. and Asem-Hiable, S. (2014). Quality of irrigation water used for urban vegetable production. In Drechsel, P. and Keraita, B. (Eds). Irrigated urban vegetable production in Ghana: characteristics, benefits and risk mitigation, p. 62-73. Colombo, Sri Lanka: International Water Management Institute (IWMI).

Khalid, M.I., Tang, J.Y.H., Baharuddin, N.H., Rahman, N.S., Rahimi, N.F. and Radu, S. (2015). Prevalence, antibiogram, and $c d t$ genes of toxigenic Campylobacter jejuni in salad style vegetables (ulam) at farms and retail outlets in Terengganu. Journal of Food Protection, 78(1), 65-71. https:// doi.org/10.4315/0362-028X.JFP-14-109

Koukkidis, G. and Freestone, P. (2018). Salmonella contamination of fresh salad produce: prevalence, impact and reduction strategies. Journal of Horticultural Science and Crop Research, 1(1), 1-8. https://doi.org/10.15744/2767-8709.1.102

Kusumaningrum, H.D., Suliantari and Dewanti-Hariyadi, R. (2012). Multidrug resistance among different serotypes of Salmonella isolates from fresh products in Indonesia. International Food Research Journal, 19(1), 57-63.

Leifert, C., Ball, K., Volakakis, N. and Cooper, J.M. (2008). Control of enteric pathogens in ready-to-eat vegetable crops in organic and 'low input' production systems: a HACCP-based approach. Journal of Applied Microbiology, 105(4), 931-950. https://doi.org/10.1111/j.1365-2672.2008.03794.x

Lertworapreecha, M., Sutthimusik, S. and Tontikapong, K. (2013). Antimicrobial resistance in Salmonella enterica isolated from pork, chicken, and vegetables in southern Thailand. Jundishapur Journal of Microbiology, 6(1), 36-41. https://doi.org/10.5812/ jjm.4312

Malaysian Dietary Guidelines. (2010). National Coordinating Committee on Food and Nutrition, p. 77-92. Putrajaya, Malaysia: Ministry of Health Malaysia

Malchione, M.D., Torres, L.M., Hartley, D.M., Koch, M. and Goodman, J.L. (2019). Carbapenem and colistin resistance in Enterobacteriaceae in Southeast Asia: Review and mapping of emerging and overlapping challenges. International Journal of Antimicrobial Agents, 54(4), 381-399. https://doi.org/10.1016/ j.ijantimicag.2019.07.019

McLauchlin, J. (2014). Risk of Salmonella and Norovirus in leafy greens eaten raw as salads. Veg-itrade, closing event: taking the safety of fresh produce to the next level, Brussels, 11-12 June 2014.
United Kingdom: Public Health England.

Mesbah Zekar, F., Granier, S.A., Marault, M., Yaici, L., Gassilloud, B., Manceau, C., Touati, A. and Millemann, Y. (2017). From Farms to Markets: Gram-Negative Bacteria Resistant to ThirdGeneration Cephalosporins in Fruits and Vegetables in a Region of North Africa. Frontiers in Microbiology, 8, 1569. https://doi.org/10.3389/ fmicb.2017.01569

Millner, P.D. (2014). Chapter 4 - manure management. In: Matthews, K.R., Sapers, G.M., Gerba, C.P. (Eds.), The Produce Contamination Problem, second ed. p. 85-106. San Diego, USA: Academic Press. https://doi.org/10.1016/B978-0-12-404611-5.00004$\mathrm{X}$

Mir, S.A., Shah, M.A., Mir, M.M., Dar, B.N., Greiner, R. and Roohinejad, S. (2018). Microbiological contamination of ready-to-eat vegetable salads in developing countries and potential solutions in the supply chain to control microbial pathogens. Food Control, 85, 235-244. https://doi.org/10.1016/ j.foodcont.2017.10.006

Mohd Noor, N., Tang, J.Y.H. and Badaluddin, N.A. (2020). Detection, isolation and antimicrobial testing of Listeria monocytogenes in chicken from wet markets in Terengganu, Malaysia. Bioscience Research, 17(SI-1), 100-109.

Monte, D.F., Lincopan, N., Fedorka-Cray, P.J. and Landgraf, M. (2019). Current insights on high priority antibiotic-resistant Salmonella enterica in food and foodstuffs: a review. Current Opinion in Food Science, 26, 35-46. https://doi.org/10.1016/ j.cofs.2019.03.004

Nguyen, T.K., Bui, H.T., Truong, T.A., Lam, D.N., Ikeuchi, S., Ly, L.K.T., Hara-Kudo, Y., Taniguchi, T. and Hayashidani, H. (2021). Retail fresh vegetables as a potential source of Salmonella infection in the Mekong Delta, Vietnam. International Journal of Food Microbiology, 341, 109049

https://doi.org/10.1016/

j.ijfoodmicro.2021.109049

Nidaullah, H., Abirami, N., Shamila-Syuhada, A.K., Chuah, L.O., Nurul, H., Tan, T.P., Abidin, F. and Rusul, G. (2017). Prevalence of Salmonella in poultry processing environments in wet markets in Penang and Perlis, Malaysia. Veterinary World, 10 (3), 286-292. https://doi.org/10.14202/ vetworld.2017.286-292

Ottesen, A.R., Gorham, S., Pettengill, J.B., Rideout, S., Evans, P. and Brown, E. (2015). The impact of systemic and copper pesticide applications on the phyllosphere microflora of tomatoes. Journal of the Science of Food and Agriculture, 95(5),1116-1125. 
https://doi.org/10.1002/jsfa.7010

Ribas, A., Weerachai Saijuntha, W., Agatsuma, T., Prantlová, V. and Poonlaphdecha, S. (2016). Rodents as a Source of Salmonella Contamination in Wet Markets in Thailand. Vector-Borne and Zoonotic Diseases, 16(8), 537-540. https://doi.org/10.1089/ vbz.2015.1894

Roshila-Murni, R. (2020). Kempen lebihkan makan ulam. Sinar Harian, $29^{\text {th }}$ June 2020, p. 22. [In Bahasa Malaysia].

Saw, S.H., Mak, J.L., Tan, M.H., Teo, S.T., Tan, T.Y., Cheow, M.Y.K., Ong, C.A., Chen, S.N., Yeo, S.K., Kuan, C.S., Son, R., New, C.Y., Phuah, E.T., Thung, T.Y. and Kuan, C.H. (2020). Detection and quantification of Salmonella in fresh vegetables in Perak, Malaysia. Food Research, 4(2), 441-448. https://doi.org/10.26656/fr.2017.4(2).316

Scott, H.M., Acuff, G., Bergeron, G., Bourassa, M.W., Gill, J., Graham, D.W., Kahn, L.H., Morley, P.S., Salois, M.J., Simjee, S., Singer, R.S., Smith, T.C., Storrs, C. and Wittum, T.E. (2019). Critically important antibiotics: criteria and approaches for measuring and reducing their use in food animal agriculture. Annals of the New York Academy of Sciences, 1441(1), 8-16. https://doi.org/10.1111/ nyas. 14058

Sebastian, R.S, Wilkinson Enns, C, Goldman, J.D, Hoy M.K, Moshfegh, A.J. (2019). Findings from What We Eat in America, National Health and Nutrition Examination Survey 2011-2014 support salad consumption as an effective strategy for improving adherence to dietary recommendations. Public Health Nutrition, 22(6), 976-987. https:// doi.org/10.1017/S1368980018003695

Shang, K., Wei, B., Jang, H-K. and Kang, M. (2019). Phenotypic characteristics and genotypic correlation of antimicrobial resistant (AMR) Salmonella isolates from a poultry slaughterhouse and its downstream retail markets. Food Control, 100, 35-45. https:// doi.org/10.1016/j.foodcont.2018.12.046

Sin, M., Yoon, S., Kim, Y.B., Noh, E.B., Seo, K.W. and Lee, Y.J. (2020). Molecular characteristics of antimicrobial resistance determinants and integrons in Salmonella isolated from chicken meat in Korea. Journal of Applied Poultry Research, 29(2), 502514. https://doi.org/10.1016/j.japr.2019.12.010

Strawn, L.K., Fortes, E.D., Bihn, E.A., Nightingale, K.K., Grohn, Y.T., Worobo, R.W., Wiedmann, M. and Bergholz, P.W. (2013). Landscape and meteorological factors affecting prevalence of three food-borne pathogens in fruit and vegetable farms. Applied and Environmental Microbiology, 79(2), 588-600. https://doi.org/10.1128/AEM.02491-12
Strawn, L.K., Gröhn, Y.T., Warchocki, S., Worobo, R.W., Bihn, E.A. and Wiedmanna, M. (2013). Risk factors associated with Salmonella and Listeria monocytogenes contamination of produce fields. Applied and Environmental Microbiology, 79(24), 7618-7627. https://doi.org/10.1128/AEM.02831-13

Tang, J.Y.H., Khalid, M.I., Aimi, S., Abu-Bakar, C.A. and Radu, S. (2016). Antibiotic resistance profile and RAPD analysis of Campylobacter jejuni isolated from vegetables farms and retail markets. Asian Pacific Journal of Tropical Biomedicine, 6(1), 7175.

Thung, T.Y., Mazlan, N., Lee, E., New, C.Y., Tan, C.W., Son, R., Rinai, K.R., Anua, S.M. and Mastor, N.N. (2020). Antimicrobial resistance profile of Salmonella present in organic farming in Selangor, Malaysia. Food Research, 4(6),2176-2180. https:// doi.org/10.26656/fr.2017.4(6).288

Verma, P., Saharan, V.V., Nimesh, S. and Singh, A.P. (2018). Phenotypic and virulence traits of Escherichia coli and Salmonella strains isolated from vegetables and fruits from India. Journal of Applied Microbiology, 125(1), 270-281. https:// doi.org/10.1111/jam.13754

Vuthy, Y., Kruy Sun Lay, K.S., Seiha, H., Kerleguer, A., Aidara-Kane, A. (2017). Antibiotic susceptibility and molecular characterization of resistance genes among Escherichia coli and among Salmonella subsp. in chicken food chains. Asian Pacific Journal of Tropical Biomedicine, 7(7), 670-674. https:// doi.org/10.1016/j.apjtb.2017.07.002

Wakabayashi, Y., Sekizuka, T., Yamaguchi, T., Fukuda, A., Suzuki, M., Kawahara, R., Taguchi, M., Kuroda, M., Semba, K., Shinomiya, H. and Kawatsu, K. (2020). Isolation and plasmid characterisation of Salmonella enterica serovar Albany harbouring mcr5 from retail chicken meat in Japan. FEMS Microbiology Letters, 367(15), 1-9. https:// doi.org/10.1093/femsle/fnaa127

WHO (World Health Organization) (2019). Critically important antimicrobials for human medicine, 6th revision. Geneva: WHO.

Yang, X., Wu, Q., Huang, J., Wu, S., Zhang, J., Chen, L., Wei, X., Ye, Y., Li, Y., Wang, J., Lei, T., Xue, L., Pang, R. and Zhang, Y. (2020). Prevalence and characterization of Salmonella isolated from raw vegetables in China. Food Control, 109, 106915. https://doi.org/10.1016/j.foodcont.2019.106915 